\title{
Permissive Role of Insulin in the Expression of Long-Term Potentiation in the Hippocampus of Immature Rats
}

\author{
Wenchao Zhao Xiaomei Wu Hui Xie Ya Ke Wing-Ho Yung \\ School of Biomedical Sciences, Faculty of Medicine, The Chinese University of Hong Kong, Shatin, Hong Kong, SAR, \\ China
}

\section{Key Words}

Insulin - Long-term potentiation - Synaptic plasticity

\begin{abstract}
Many studies indicate that impairment in insulin signaling leads to learning and memory deficits. However, previous studies failed to establish a clear role of insulin in long-term potentiation (LTP), the best cellular model of memory formation. Here we show that while insulin pretreatment did not affect LTP magnitude in the adult rat hippocampus, it facilitated LTP expression in the immature hippocampus. The tyrosine kinase inhibitor AG-1024 abolished the effect of insulin in young rats, suggesting the involvement of the insulin receptor. On the other hand, increasing extracellular glucose concentration failed to facilitate LTP and application of an insulin-responsive glucose transporter-4 inhibitor did not impair the effect of insulin. These results suggest that the facilitatory action of insulin on LTP is not an indirect effect on glucose homeostasis/utilization. Involvement of the MAPK/ERK pathway, a known downstream pathway of insulin signaling, was revealed by pretreatment with PD98059, which blocked the insulin-mediated LTP facilitation. Consistent with this, high-frequency stimulation induced a significant increase in the level of phosphorylated Erk-2 in insulin-
\end{abstract}

treated hippocampus. Taken together, these results suggest that insulin may be an essential factor in the immature brain, allowing the expression of LTP to facilitate learning and memory.

Copyright $\odot 2011$ S. Karger AG, Basel

\section{Introduction}

The role of insulin as a neuromodulator and neurotrophic factor in the brain has received much attention in recent years [1-4]. The interest in a central action of insulin was prompted by the early unexpected finding that the brain contains insulin and insulin receptors [5-8], and the increased awareness of a possible causal link between insulin resistance and cognitive deficits in diabetes $[2,9]$. Furthermore, there is evidence that defective insulin signaling contributes to the pathophysiology of $\mathrm{Alz}$ heimer's disease [10-13].

Experimental studies in humans and animals in general point to a facilitatory role of insulin in cognitive performance. For example, administration of insulin intra-nasally or by infusion in humans $[14,15]$ and via intracerebroventricular injection in rats [16] resulted in elevated insulin levels in the brain and enhancement of

\section{KARGER}

Fax +4161306 1234

E-Mail karger@karger.ch

www.karger.com
(C) 2011 S. Karger AG, Basel

1424-862X/10/0184-0236\$26.00/0

Accessible online at:

www.karger.com/nsg
W.H. Yung

School of Biomedical Sciences, Faculty of Medicine

The Chinese University of Hong Kong

Shatin, Hong Kong, SAR (China)

Tel. +852 2608 6880, E-Mail whyung@ @ cuhk.edu.hk 
memory functions. Insulin also exerts a restorative action on memory impairment in various settings, including drug-induced experimental model of diabetes $[17,18]$, models of stress [19] and also in Alzheimer's disease patients [20]. These findings are consistent with the observation that insulin receptors are especially abundant in the hippocampus in both rats and humans [21-24] and that insulin receptors on pyramidal neurons are upregulated after training in the water maze task [25].

It is widely accepted that long-term synaptic plasticity in the hippocampus, especially long-term potentiation (LTP), is the mechanism that underlies some forms of learning and memory. In the hippocampus, insulin receptor immunoreactivity and insulin binding sites are particularly prominent in the CA1 subfield $[26,27]$. However, although a role of insulin in inducing a long-term depression-like phenomenon has been well documented in the hippocampus [28], the effect of insulin on LTP remains unclear. In fact, it has been shown that insulin does not facilitate high-frequency stimulation (HFS)-induced LTP [29]. Also, although some studies show that in experimental diabetes, LTP is impaired and can be rescued by insulin $[17,30]$, there are reports showing that LTP is preserved in this condition [e.g. 31]. Thus, the exact relationship between insulin and LTP is still obscure.

In this study, we addressed the question of whether insulin application has any effect on LTP expression in the hippocampus of normal, healthy rats. Since it is known that insulin receptor expression in the brain is developmentally regulated, being highest in young age and decreasing with age $[1,32]$, we examined and compared the effect of insulin on LTP in both immature and adult rats. Our experiments reveal that insulin plays a critical permissive role in LTP expression in the immature brain via insulin receptors but not through its influence on glucose utilization/homeostasis. This finding suggests that insulin may be an indispensible endogenous factor allowing LTP expression in normal young animals for learning and memory, and provides an explanation for the impaired cognitive function in children with insulin-dependent type 1 diabetes [33].

\section{Materials and Methods}

All experimental protocols and procedures described were performed in compliance with the National Institutes of Health Guidelines for the Care and Use of Laboratory Animals and were approved by the Animal Experimentation Ethical Committee of the Chinese University of Hong Kong. Efforts were made to minimize the number of animals used and their suffering.

\section{Hippocampal Brain Slices}

Sprague-Dawley rats, provided by the Laboratory Animal Services Center of the Chinese University of Hong Kong, were anesthetized with isoflurane, and then sacrificed by decapitation. The brains were immediately removed and cut into two halves in the sagittal plane and then immersed in ice-cold artificial cerebrospinal fluid (ACSF) of the following composition: $125 \mathrm{mM} \mathrm{NaCl}, 2.0$ $\mathrm{mm} \mathrm{KCl}, 1.2 \mathrm{~mm} \mathrm{MgSO}_{4}, 2.5 \mathrm{mM} \mathrm{CaCl}_{2}, 1.2 \mathrm{mM} \mathrm{KH}_{2} \mathrm{PO}_{4}, 11 \mathrm{mM}$ glucose, and $26 \mathrm{mM} \mathrm{NaHCO}_{3}$, which was continuously bubbled with $95 \% \mathrm{O}_{2}$ and $5 \% \mathrm{CO}_{2}$ (pH 7.4; osmolarity 290-310 mosm). The brains were then glued with the lateral side down onto a platform in a chamber filled with oxygenated ice-cold ACSF, and 300- $\mu \mathrm{m}$ thick parasagittal sections were cut using a vibrating microtome (Integraslice 7550MM, Campden Instruments Ltd., Loughborough, UK). Slices were preincubated in a holding chamber containing oxygenated ACSF at $34 \pm 1^{\circ} \mathrm{C}$ for at least $1 \mathrm{~h}$.

\section{LTP Measurements}

A planar multielectrode recording setup (MED64 system, Alpha Med Sciences Co., Ltd, Tokyo, Japan) was employed to record the field excitatory postsynaptic potential (fEPSP), and to study LTP. The methodology has been described in details elsewhere $[34,35]$. Briefly, hippocampal slices were placed on special probes that were fabricated with $8 \times 8$ electrode arrays $(20 \times 20 \mu \mathrm{m}$, made of indium tinoxide and platinum black) and precoated with polyethylenimine (Sigma). The P210A probes (Alpha Med Sciences) with an interelectrode distance of $100 \mu \mathrm{m}$ were routinely used. Correct placement of the electrodes at the CA3-CA1 region was done manually, monitored by a microscope (MIC-D, Olympus Ltd., Japan). To increase the efficiency of the experiments and to minimize the variation in the results arising from differences in incubation times, a maximum of 4 slices were studied simultaneously by means of a splitter provided by the manufacturer. Each slice was submerged in and superfused with oxygenated ACSF at a flow rate of $1.3-1.5 \mathrm{ml} / \mathrm{min}$. fEPSPs were recorded from the dendritic layer of CA1 neurons by choosing an electrode in the Schaffer collateral pathway as the stimulating electrode. Based on the stimulus-response curve, we chose a stimulation intensity that evoked the fEPSP with a magnitude of $30-40 \%$ of the maximum response. After allowing a stable baseline of $30 \mathrm{~min}$ in which the stimulus was delivered every $60 \mathrm{~s}$, an LTP induction protocol consisting of 1 train of $100-\mathrm{Hz}$ stimuli that lasted for $1 \mathrm{~s}$ was applied, and the field potential response after the tetanus was recorded for $1 \mathrm{~h}$. The magnitude of LTP was quantified as percentage change in the average amplitude of the fEPSP taken at 50- to 60-min intervals after LTP induction. Drugs were applied to the slices for at least $30 \mathrm{~min}$ before the delivery of HFS.

\section{Protein Analyses}

After preparation of hippocampal slices from young rats, the CA1 regions from 5-7 slices were cut and incubated with radioimmunoprecipitation assay lysis buffer including Pimix (1:200 dilution) and 0.1 M phenylmethylsulfonyl fluoride (1:100 dilution) for $30 \mathrm{~min}$. After centrifugation at 13,000 rpm for $15 \mathrm{~min}$, the supernatant was measured for the concentration of protein and was then subjected to SDS-PAGE (10\% polyacrylamide gel electrophoresis). The protein was transferred to nitrocellulose membrane using an electrophoretic transfer system. The membrane was blocked with Tris-buffered saline mixed with Tween-20 including $5 \%$ milk for $1 \mathrm{~h}$ followed by overnight incubation at $4^{\circ} \mathrm{C}$ 
with rabbit primary antibody against MAPK/ERK and phosphoMAPK/ERK $(1: 3,000)$. The membrane was stripped in $50 \mathrm{ml}$ stripping buffer at $50^{\circ} \mathrm{C}$ and shaken for at least $30 \mathrm{~min}$ until no signal could be detected. After incubation with goat anti-rabbit IRDye $800 \mathrm{CW}$ secondary antibody (1:10,000, Li-Cor) for $1 \mathrm{~h}$ at room temperature, the membrane was scanned by an Odyssey scanner. The intensities of the specific bands were analyzed by Odyssey infrared imaging software at a resolution of $169 \mu \mathrm{m}$. Each experiment was performed three times.

\section{Chemicals and Data Analysis}

Insulin was purchased from Sigma (USA). Indinavir was obtained from TRC (Canada). PD98059 was purchased from Cayman (USA) and AG1024 was from Spectrum (USA). MAPK (Erk) antibodies and phospho-MAPK (p-Erk) antibodies were obtained from Cell Signaling Technology Company (USA). The fEPSPs obtained were analyzed using Prism 4.0 (GraphPad software, San Diego, Calif., USA). The data are expressed as means \pm SEM and $n$ stands for the number of brain slices used. An unpaired Student's t test was used to compare LTP magnitude between two groups; ANOVA was used to compare LTP amplitude for multiple groups followed by a Newman-Keuls test.

\section{Results}

\section{Differential Effects of Insulin on LTP in Young and}

Adult Rats

We first examined the ability of the hippocampal slices from 2-month-old (adult) and 11- to 12-day-old (young) rats to exhibit LTP. After baseline recording for at least 30 min, standard HFS $(100 \mathrm{~Hz}, 1 \mathrm{~s})$ stimuli were delivered to the Schaffer collateral pathway and fEPSPs were recorded in the CA1 dendritic layer for at least $60 \mathrm{~min}$. As shown in figure 1a, in the adult group, the fEPSP amplitude was potentiated to $165.8 \pm 13.0 \%$ of baseline (12 slices, 8 rats). On the other hand, HFS failed to induce potentiation of the fEPSP in the young rat measured at the end of $60 \mathrm{~min}$ (fig. $1 \mathrm{~b}, 100.3 \pm 6.4 \%$ of baseline, 8 slices, 4 rats).

To test the effect of insulin on LTP, some hippocampal slices from both age groups were pretreated with insulin ( 0.08 or $0.8 \mathrm{ng} / \mathrm{ml}$, equivalent to 13.7 and $137 \mathrm{nM}$, respectively) for at least $1 \mathrm{~h}$ before delivery of HFS. Insulin at these concentrations did not affect the baseline fEPSPs. As shown in figure 1a, in the adult group, the magnitude of LTP was not altered by insulin at both $0.08 \mathrm{ng} / \mathrm{ml}$ $(158.5 \pm 14.4 \%, 8$ slices 5 rats, $\mathrm{p}=0.64$ compared with control) and the higher concentration of $0.8 \mathrm{ng} / \mathrm{ml}(149.3$ $\pm 4.3 \%, 10$ slices 5 rats, $\mathrm{p}=0.59$ compared with control). Strikingly, however, in the young rats in which HFS could not induce LTP, pretreatment with insulin induced potentiation of the fEPSP in a dose-dependent manner (fig. 1b). At a concentration of $0.08 \mathrm{ng} / \mathrm{ml}$, the fEPSP mea- sured at the end of $60 \mathrm{~min}$ was $102.6 \pm 3.4 \%$ of baseline (fig. $1 b, 9$ slices from 6 rats, $p=0.77$ compared with control). Significant potentiation of the fEPSP, i.e. LTP, was enabled at an insulin concentration of $0.8 \mathrm{ng} / \mathrm{ml}$. The amplitude of the fEPSP at 60 min after HFS was $120.4 \pm$ $4.4 \%$ of baseline (fig. 1 b, 10 slices from 6 rats, $p<0.01$, compared with control). These results indicate that under the experimental conditions of the present study, insulin plays a permissive role in the LTP expression in young rats while it is without effect on the LTP in the adult hippocampus.

\section{The Facilitatory Effect of Insulin Is Mediated by the Insulin Receptor}

To determine the involvement of the insulin receptor in mediating the effect of insulin on synaptic plasticity, we studied the effect of AG-1024, a tyrosine kinase inhibitor known to inhibit the insulin receptor [36], on the observed insulin-dependent LTP in the young rats. Incubation of the hippocampal slices with AG-1024 (80 nM) did not affect the basal synaptic transmission. However, as shown in figure $2 \mathrm{a}$, pretreatment of the slices with AG1024 for $30 \mathrm{~min}$ before HFS and throughout the experiment largely abolished the insulin-dependent LTP. The magnitude of LTP in the presence of AG-1024 was 105.8 $\pm 2.5 \%$ (15 slices from 9 rats), which was significantly lower than that of the insulin-alone group (fig. 2a, 130.4 $\pm 5.7 \%$; 14 slices from 7 rats, $\mathrm{p}<0.001$ ).

We also tested the effect of AG-1024 on the LTP expressed by the adult hippocampus. In the control group, the LTP magnitude was $143.8 \pm 9.4 \%$ (fig. $2 \mathrm{~b}, 12$ slices from 6 rats). Treatment with AG-1024 did not affect the LTP $(148.6 \pm 8.3 \%, 11$ slices 6 rats, $p=0.71$; fig. $2 b)$. These results indicate that AG-1024 itself does not have a direct effect on LTP and is in line with the notion that the LTP expressed in the adult hippocampus is not dependent on insulin.

\section{The Facilitation of LTP Expression Is Not via}

\section{Regulation of Glucose Utilization}

The effect of insulin on glucose metabolism in the brain is uncertain, and is still debated [37,38]. To address the possibility that the facilitatory action of insulin on LTP expression in the young animals is via its effect on glucose utilization, we performed two sets of experiments. In the first experiment, we studied the effect of indinavir, an insulin-sensitive glucose transporter-4 (GLUT-4) inhibitor. In the insulin-treated group, the magnitude of LTP was $122.2 \pm 4.9 \%$ (fig. 3a, 10 slices from 5 rats). Preincubation of the slices with indinavir 

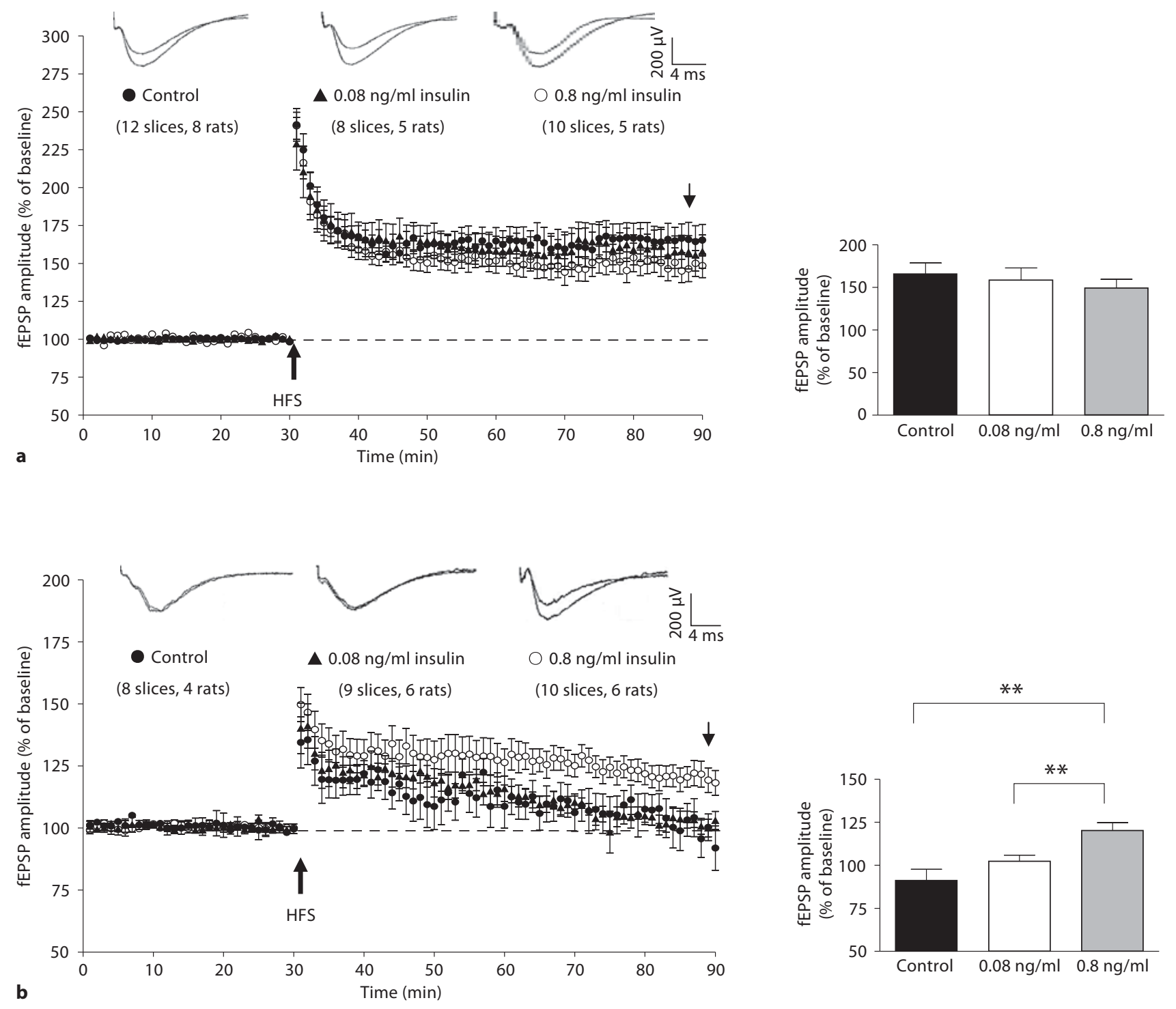

Fig. 1. Different effects of insulin on hippocampal LTP in mature and immature rats. a Left panel: fEPSPs recorded from the hippocampal CA1 region of 2-month-old rats showed that LTP was induced by conventional HFS delivered to the Schaffer collateral pathway at $30 \mathrm{~min}$ after stable baseline recording. The presence of insulin in the ACSF $(0.08$ and $0.8 \mathrm{ng} / \mathrm{ml})$ did not affect the magnitude of the LTP. The results are summarized in the right panel. Representative recordings are shown in the insets, sampled during the baseline and at the time indicated by the arrow. b The same
HFS failed to induce LTP in the hippocampus of young (11-12 days) rats, but insulin at $0.8 \mathrm{ng} / \mathrm{ml}$ facilitated the expression of LTP. Statistical analysis shown in the right panel shows that the averaged amplitude of fEPSPs measured in the last $10 \mathrm{~min}$ of recording in the $0.8 \mathrm{ng} / \mathrm{ml}$ group was significantly higher than those of the control and the low-concentration $(0.08 \mathrm{ng} / \mathrm{ml})$ group. Insulin was applied for at least $1 \mathrm{~h}$ before the delivery of HFS and was present throughout the experiment, ${ }^{* *} \mathrm{p}<0.01$. 

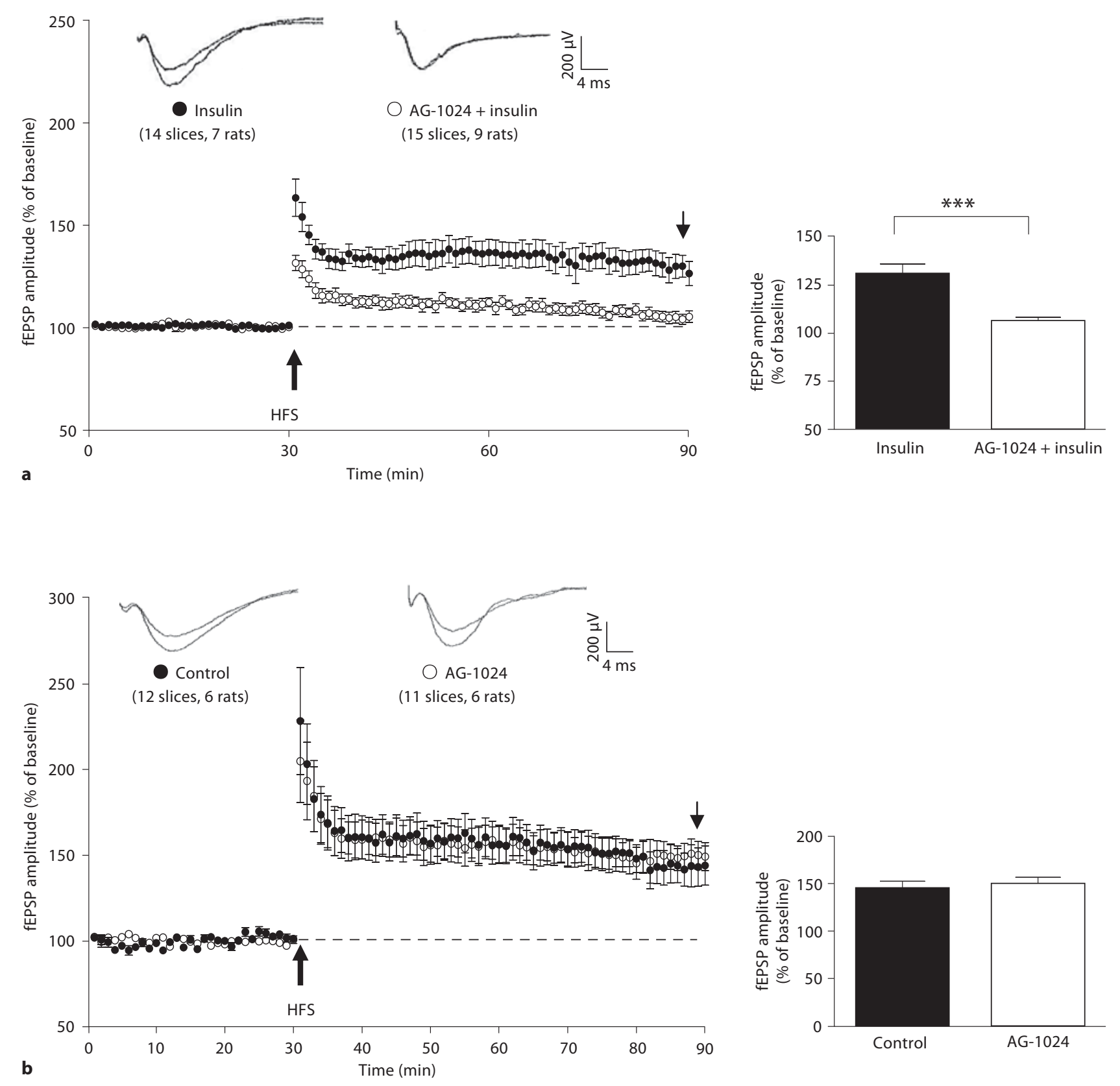

Fig. 2. The facilitatory effect of insulin on LTP in immature rats is mediated by insulin receptor. a Incubation of the hippocampal slices with AG-1024 (80 nM), an inhibitor of insulin receptor, significantly decreased the magnitude of insulin-mediated LTP in the young rats. Representative traces are shown in the insets, sampled during the baseline and at the time indicated by the arrow. Statistical analysis shown in the right panel shows that the aver- aged amplitude of fEPSPs measured in the last 10 min of recording in the AG-1024-treated group was significantly lower than the insulin group. b In the mature rats, AG-1024 failed to alter the magnitude of the LTP. AG-1024 was applied for $30 \mathrm{~min}$ before HFS delivery and was present throughout the experiments, *** $\mathrm{p}<0.001$. 
Fig. 3. The facilitatory action of insulin on LTP is not via its effect on glucose utilization. a Application of indinavir $(100 \mu \mathrm{M})$, an inhibitor of the insulin-sensitive GLUT4, did not affect the magnitude of insulindependent LTP in young rats. b Doubling and tripling the concentration of glucose from 11 to 22 and $33 \mathrm{~mm}$, respectively, did not facilitate the expression of LTP. Representative traces are shown in the insets, sampled during the baseline and at the time indicated by the arrow. Indinavir was applied for $30 \mathrm{~min}$ prior HFS delivery and was present throughout the experiment.

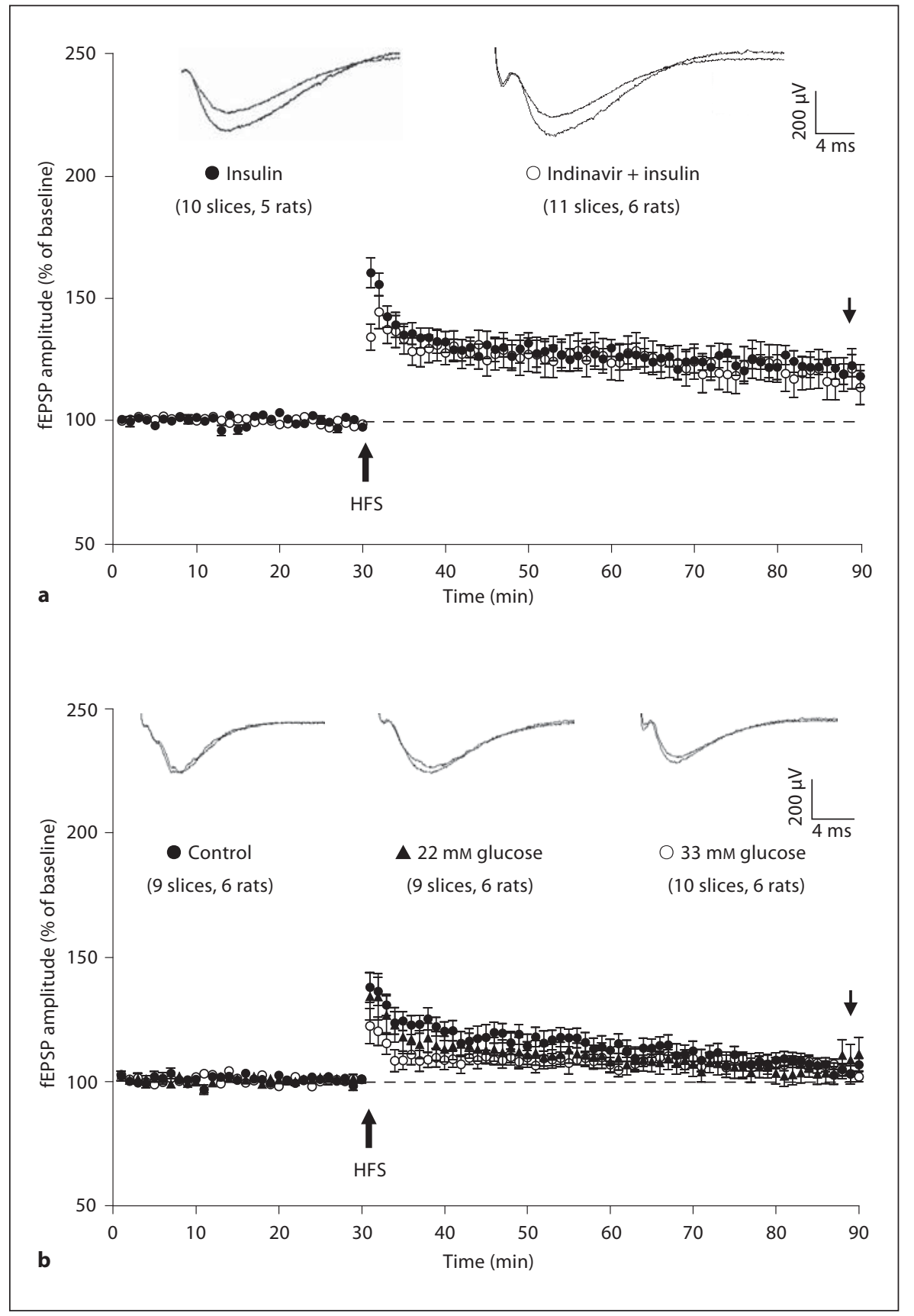

$(100 \mu \mathrm{M})$ for over $30 \mathrm{~min}$ did not affect the magnitude of LTP observed (118.7 \pm 9.1\%, 11 slices from 6 rats, $\mathrm{p}=$ $0.75)$. In the brain, uptake of glucose is mainly dependent on facilitated glucose transport, which is driven by the glucose concentration gradient across the cell membrane. Thus, to assess the impact of increased glucose uptake per se, we tested the effect of raising extracellular glucose concentration on the expression of LTP in the young rats.
As shown in figure $3 \mathrm{~b}$, increasing the glucose concentration from 11 to 22 or $33 \mathrm{~mm}$ did not affect the magnitude of LTP in young rats $(104.6 \pm 3.2 \%, 9$ slices from 6 rats, $\mathrm{p}=0.79$ and $106.7 \pm 2.2 \%, 10$ slices from 6 rats, $\mathrm{p}=0.87$, respectively). Taken together, these data strongly suggest that the facilitatory action of insulin on LTP expression is not an indirect effect via the regulation of glucose availability to the neurons. 
Fig. 4. Involvement of Erk-2 activation in the insulin-dependent LTP. a Pretreatment of the MEK inhibitor PD98059 (20 $\mu \mathrm{M})$ significantly decreased the magnitude of insulin-mediated LTP in the immature rats. b Western blot analysis showed that $8 \mathrm{~min}$ after the delivery of HFS, there was an increase in the expression of phosphorylated Erk-2 (p-Erk-2, or p42 MAPK) only in those hippocampal slices incubated with insulin $(0.8 \mathrm{ng} / \mathrm{ml})$. c Statistical analysis revealed that Erk-2, in contrast to Erk-1, is specifically activated by the combined HFS and insulin treatment, ${ }^{*} \mathrm{p}<0.05(\mathrm{n}=3)$.

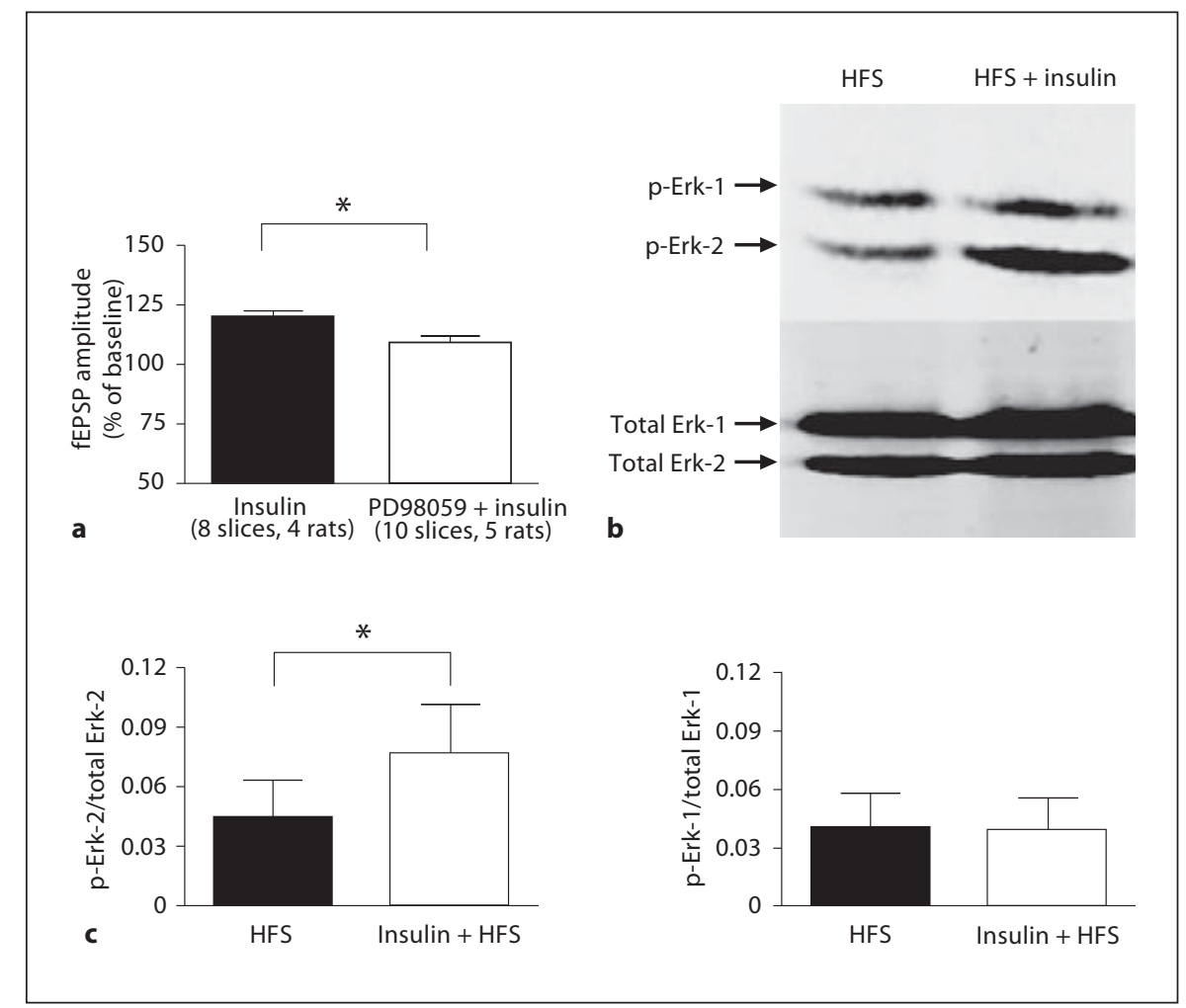

\section{Involvement of the MAPK/ERK Pathway}

We next explored the intracellular signaling pathway of the insulin-dependent LTP. Specifically, we tested the involvement of the MAPK/ERK pathway, which has been shown to be a major signaling pathway mediating the effect of insulin in the peripheral organs [39]. Figure 4a shows that in the insulin treatment group, the average magnitude of fEPSP obtained in 8 slices from 4 rats was $119.4 \pm 3.2 \%$. When PD98059 $(20 \mu \mathrm{M})$, an inhibitor of MEK1, was applied before and continued throughout the experiment, the LTP magnitude was reduced to $106.6 \pm$ $3.3 \%$ (10 slices from 5 rats, $p<0.05$ ). To further confirm the involvement of the MAPK/ERK pathway in the effect of insulin, we examined the expression of phosphorylated Erk1/2 in the hippocampus of young rats after HFS stimulation by Western blot analysis. As shown in figure $4 \mathrm{~b}$, in the presence of insulin, the expression of phosphorylated Erk-2 (p42 MAPK) in the hippocampal slices was increased $8 \mathrm{~min}$ after the delivery of HFS. Analysis showed that the ratio of phosphorylated Erk-2 versus total Erk-2 increased significantly in the presence of insulin compared with that in control group (fig. 4c, $0.077 \pm$ 0.025 vs. $0.045 \pm 0.019, \mathrm{n}=3, \mathrm{p}<0.05)$. However, the ratio of phosphorylated Erk-1 (p44 MAPK) versus total Erk-
1 was not significantly different from that of the control group (fig. $4 \mathrm{c}, 0.038 \pm 0.017$ vs. $0.041 \pm 0.017, \mathrm{n}=3, \mathrm{p}>$ $0.05)$.

\section{Discussion}

Despite different lines of evidence supporting a role of insulin in facilitating learning and memory, the relationship between insulin and LTP, the best cellular candidate underlying memory formation, remains elusive up to date. By investigating the action of insulin on the expression of hippocampal LTP in healthy adult and young rats, we show that insulin plays a permissive role in the expression of LTP in young rats but has a minimal effect in adult rats. This conclusion is based on the fact that the hippocampus from 11- to 12-day-old rats, in response to the conventional HFS paradigm, produced a small increase in fEPSP magnitude that was not sustained. However, addition of $0.8 \mathrm{ng} / \mathrm{ml}$ (or $137 \mathrm{nM}$ ) of insulin allowed the expression of a decent LTP, which amounted to over $20 \%$ of potentiation in fEPSP. On the other hand, insulin application had no effect on the magnitude of the LTP in the adult hippocampus, which is in agreement with previous studies $[29,40]$. 
These findings lead to some interesting speculations. First, it has been shown by others [41-43] and also in the present study that hippocampal slices from rats younger than 2 weeks are much weaker in the ability to express LTP, and therefore are regarded as developmentally immature. Our study suggests that the hippocampus at 1112 days is equipped with the machinery to express LTP in response to the standard one-train HFS. The fact that they could not express LTP could be due to the removal of endogenous factors like insulin from the incubation fluid rather than to an inherent deficit. Second, insulin as a neuromodulator is particularly important for learning and memory in young subjects. This speculation is in line with the observation that the expression of insulin receptor is developmentally regulated, being highest in early postnatal stages and decreasing with age $[1,32]$, and can explain the cognitive dysfunction found in children with type 1 diabetes in which there is deficiency in insulin production $[33,44,45]$. In the adult hippocampus, it is possible that other factors, e.g. brain-derived neurotrophic factor, or mechanisms serve to ensure the expression of LTP which as a result relies less on insulin.

Our results imply the involvement of the insulin receptor in mediating the insulin-dependent LTP. This is based on the fact that AG-1024 and the MAPK/ERK pathway inhibitor PD98059 significantly suppressed the effect of insulin. However, due to the similarity between the insulin receptor and that of insulin-like growth factor-1 (IGF-1), and that both insulin and IGF-1 can act on these two types of receptors, we cannot rule out a role of IGF-1. In fact, the tyrosine kinase inhibitor AG-1024 inhibits both receptors. However, since the expression of the insulin receptor and the IGF-1 receptor within the hippocampus is different, with the insulin receptor being higher in the CA1 region [21], it is likely that insulin is the more important endogenous factor in permitting the expression of LTP in the CA3-CA1 pathway in vivo.

What is the mechanism enabling insulin to facilitate the expression of LTP? It is well known that glucose is the main nutrient and energy source of neurons. The brain has traditionally been regarded as an insulin-insensitive organ [46] because the main glucose transporters expressed centrally are glucose transporter-1 (or GLUT-1) and glucose transporter-3 (or GLUT-3), both of which are insulin insensitive. However, recent studies suggest the presence of the insulin-responsive GLUT-4 in the brain, and insulin can induce GLUT-4 translocation to the plasma membrane in neurons, including those in the hippocampus [47-51]. Therefore, an insulin-induced increase in glucose utilization and therefore an increase in energy supply is a possible mechanism underlying the facilitatory effect of insulin on LTP. Our study, however, is not in favor of this scenario because neither elevating the concentration of glucose in the ACSF nor incubation with the GLUT- 4 inhibitor indinavir $[52,53]$ affected the magnitude of the insulin-dependent LTP. It remains possible that GLUT-4 plays a role under high metabolic requirement, which is not reached in the in vitro slice condition. Alternatively, GLUT-4-mediated glucose uptake may be related to growth and development rather than long-term synaptic plasticity.

There are other potential mechanisms by which insulin can facilitate the expression of LTP. For example, it has been found that insulin promotes cell surface expression of N-methyl-D-aspartic acid (NMDA) receptors [54] and the GluR1 $\alpha$-amino-3-hydroxy-5-methyl-4-isoxazolepropionic acid (AMPA) receptor subunit [55]; both can lead to enhanced synaptic transmission. Insulin also enhances NMDA receptor-mediated current in hippocampal neurons [56]. These effects could lower the threshold for the induction of LTP in the hippocampus and allow its expression in response to the HFS. Interestingly, both the activity of the NMDA receptor and the expression of the GluR1 AMPA receptor subunit can be increased in an MAPK-dependent manner [57, 58]. Consistent with these observations, our results revealed that activation of Erk-2 (p42 MAPK) might be involved in the facilitatory effect of insulin on LTP. Insulin may also facilitate the expression of LTP by increasing the protein expression of the dendritic scaffolding protein PSD-95 [59] and the recruitment of the insulin receptor substrate IRSp53, which has been shown to be translocated to the synapses in response to neuronal activity [60]. Obviously, further work is needed to dissect the detailed mechanism.

In conclusion, our results identify an acute, restorative action of insulin on LTP expression in young animals, suggesting its importance in the synaptic plasticity, and therefore learning and memory, of the immature brain. This finding highlights a new facet of insulin signaling in addition to the growing belief that this protein is important for synapse maturation and maintenance during development [1]. Since cognitive impairment is a common feature in children suffering from insulin-dependent diabetes, elucidating the role of insulin in the developing nervous system is important both scientifically and clinically.

\section{Acknowledgement}

This work was supported by a grant from the Research Grants Council of Hong Kong (CUHK478308) awarded to W.H. Yung. 


\section{References}

$>1$ Chiu SL, Cline HT: Insulin receptor signaling in the development of neuronal structure and function. Neural Dev 2010;15:7.

$\checkmark 2$ Kodl CT, Seaquist ER: Cognitive dysfunction and diabetes mellitus. Endocr Rev 2008; 29:494-511.

$>3$ McNay EC: Insulin and ghrelin: peripheral hormones modulating memory and hippocampal function. Curr Opin Pharmacol 2007;7:628-632.

-4 Van der Heide LP, Ramakers GM, Smidt MP: Insulin signaling in the central nervous system: learning to survive. Prog Neurobiol 2006;79:205-221

$>5$ Margolis RU, Altszuler N: Insulin in the cerebrospinal fluid. Nature 1967;215:13751376.

6 Posner BI, Kelly PA, Shiu RP, Friesen HG: Studies of insulin, growth hormone and prolactin binding: tissue distribution, species variation and characterization. Endocrinology $1974 ; 95: 521-531$.

$>7$ Havrankova J, Roth J, Brownstein M: Insulin receptors are widely distributed in the central nervous system of the rat. Nature 1978; 272:827-829.

-8 Havrankova J, Schmechel DE, Roth J, Brownstein M: Identification of insulin in the rat brain. Proc Natl Acad Sci USA 1978; 75:5737-5741.

$>9$ Winocur G, Greenwood CE, Piroli GG, Grillo CA, Reznikov LR, Reagan LP, McEwen BS: Memory impairment in obese Zucker rats: an investigation of cognitive function in an animal model of insulin resistance and obesity. Behav Neurosci 2005;119:1389-1395.

10 Hoyer S: The brain insulin signal transduction system and sporadic (type II) Alzheimer disease: an update. J Neural Transm 2002; 109:341-360.

11 Gasparini L, Xu H: Potential roles of insulin and IGF-1 in Alzheimer's disease. Trends Neurosci 2003;26:404-406.

12 de la Monte SM, Wands JR: Alzheimer-associated neuronal thread protein mediated cell death is linked to impaired insulin signaling. J Alzheimers Dis 2004;6:231-242.

13 Craft S, Peskind E, Schwartz MW, Schellenberg GD, Raskind M, Porte D Jr: Cerebrospinal fluid and plasma insulin levels in Alzheimer's disease. Neurology 1998;50:164168 .

$\checkmark 14$ Benedict C, Hallschmid M, Schultes B, Born J, Kern W: Intranasal insulin to improve memory function in humans. Neuroendocrinology 2007;86:136-142.

- 15 Kern W, Peters A, Fruehwald-Schultes B, Deininger E, Born J, Fehm HL: Improving influence of insulin on cognitive functions in humans. Neuroendocrinology 2001;74: 270-280.

16 Park CR, Seeley RJ, Craft S, Woods SC: Intracerebroventricular insulin enhances memory in a passive-avoidance task. Physiol Behav 2000;68:509-514.
17 Biessels GJ, Kamal A, Urban IJA, Spruijt BM, Erkelens DW, Gispen WH: Water maze learning and hippocampal synaptic plasticity in streptozotocin-diabetic rats: effects of insulin treatment. Brain Res 1998;800:125135.

18 Dou JT, Chen M, Dufour F, Alkon DL, Zhao WQ: Insulin receptor signaling in long-term memory consolidation following spatial learning. Learn Mem 2005;12:646-655.

19 Moosavi M, Naghdi N, Maghsoudi N, Zahedi Asl S: Insulin protects against stress-induced impairments in water maze performance. Behav Brain Res 2007;176:230-236.

20 Craft S, Asthana S, Newcomer JW, Wilkinson CW, Matos IT, Baker LD, Cherrier M, Lofgreen C, Latendresse S, Petrova A, Plymate S, Raskind M, Grimwood K, Veith RC: Enhancement of memory in Alzheimer disease with insulin and somatostatin, but not glucose. Arch Gen Psychiatry 1999;56:11351140 .

21 Bondy CA, Bach MA, Lee WH: Mapping of brain insulin and insulin-like growth factor receptor gene expression by in situ hybridization. Neuroprotocols 1992;1:240-249.

22 Marks JL, Porte D Jr, Stahl WL, Baskin DG: Localization of insulin receptor mRNA in rat brain by in situ hybridization. Endocrinology 1990;127:3234-3236.

23 Hopkins DF, Williams G: Insulin receptors are widely distributed in human brain and bind human and porcine insulin with equal affinity. Diabet Med 1997;14:1044-1050.

24 Zhao WQ, Alkon DL: Role of insulin and insulin receptor in learning and memory. Mol Cell Endocrinol 2001;177:125-134.

25 Zhao W, Chen H, Xu H, Moore E, Meiri N, Quon MJ, Alkon DL: Brain insulin receptors and spatial memory. Correlated changes in gene expression, tyrosine phosphorylation, and signaling molecules in the hippocampus of water maze trained rats. J Biol Chem 1999; 274:34893-34902.

26 Unger J, McNeill TH, Moxley RT 3rd, White M, Moss A, Livingston JN: Distribution of insulin receptor-like immunoreactivity in the rat forebrain. Neuroscience 1989;31:143157.

27 Doré S, Kar S, Rowe W, Quirion R: Distribution and levels of $\left[{ }^{125} \mathrm{I}\right] \mathrm{IGF}-\mathrm{I},\left[{ }^{125} \mathrm{I}\right] \mathrm{IGF}-\mathrm{II}$ and $\left[{ }^{125} \mathrm{I}\right]$ insulin receptor binding sites in the hippocampus of aged memory-unimpaired and -impaired rats. Neuroscience 1997;80: 1033-1040.

$>28$ Huang CC, Lee CC, Hsu KS: An investigation into signal transduction mechanisms involved in insulin-induced long-term depression in the CA1 region of the hippocampus. J Neurochem 2004;89:217-231.

-29 Lee CC, Kuo YM, Huang CC, Hsu KS: Insulin rescues amyloid $\beta$-induced impairment of hippocampal long-term potentiation. Neurobiol Aging 2009;30:377-387.
30 Biessels GJ, Kamal A, Ramakers GM, Urban IJ, Spruijt BM, Erkelens DW, Gispen WH: Place learning and hippocampal synaptic plasticity in streptozotocin-induced diabetic rats. Diabetes 1996;45:1259-1266.

31 Bélanger A, Lavoie N, Trudeau F, Massicotte G, Gagnon S: Preserved LTP and water maze learning in hyperglycaemic-hyperinsulinemic ZDF rats. Physiol Behav 2004;83:483494.

32 Park CW, Yoo KY, Hwang IK, Choi JH, Lee $\mathrm{CH}$, Park OK, Cho JH, Lee YL, Shin HC, Won $\mathrm{MH}$ : Age-related changes in the insulin receptor beta in the gerbil hippocampus. Neurochem Res 2009;34:2154-2162.

33 Shehata G, Eltayeb A: Cognitive function and event-related potentials in children with type 1 diabetes mellitus J Child Neurol 2010; 25:469-474.

34 Oka H, Shimono K, Ogawa R, Sugihara H, Taketani M: A new planar multielectrode array for extracellular recording: application to hippocampal acute slice. J Neurosci Methods 1999;93:61-67.

35 Shimono K, Baudry M, Ho L, Taketani M, Lynch G: Long-term recording of LTP in cultured hippocampal slices. Neural Plast 2002; 9:249-254

36 Parrizas M, Gazit A, Levitzki A, Wertheimer E, LeRoith D: Specific inhibition of insulinlike growth factor-1 and insulin receptor tyrosine kinase activity and biological function by tyrphostins. Endocrinology 1997; 138:1427-1433.

37 Laron Z: Insulin and the brain. Arch Physiol Biochem 2009;15:112-116.

38 Biessels GJ, Bravenboer B, Gispen WH: Glucose, insulin and the brain: modulation of cognition and synaptic plasticity in health and disease: a preface. Eur J Pharmacol 2004; 490:1-4.

39 Saltiel AR, Kahn CR: Insulin signalling and the regulation of glucose and lipid metabolism. Nature 2001;414:799-806.

40 Van der Heide LP, Kamal A, Artola A, Gispen WH, Ramakers GM: Insulin modulates hippocampal activity-dependent synaptic plasticity in a $\mathrm{N}$-methyl-D-aspartate receptor and phosphatidyl-inositol-3-kinase-dependent manner. J Neurochem 2005;94:11581166.

41 Harris KM, Teyler TJ: Developmental onset of long-term potentiation in area CA1 of the rat hippocampus. J Physiol 1984;346:27-48.

42 Jackson PS, Suppes T, Harris KM: Stereotypical changes in the pattern and duration of long-term potentiation expressed at postnatal days 11 and 15 in the rat hippocampus. J Neurophysiol 1993;70:1412-1419.

43 Lu YF, Hayashi Y, Moriwaki A, Tomizawa K, Matsui H: FK506, a Ca ${ }^{2+} /$ calmodulin-dependent phosphatase inhibitor, inhibits the induction of long-term potentiation in the rat hippocampus. Neurosci Lett 1996;205: 103-106. 
-44 Gaudieri PA, Chen R, Greer TF, Holmes CS: Cognitive function in children with type 1 diabetes: a meta-analysis. Diabetes Care 2008;31:1892-1897.

-45 Naguib JM, Kulinskaya E, Lomax CL, Garralda ME: Neuro-cognitive performance in children with type 1 diabetes - a metaanalysis. J Pediatr Psychol 2009;34:271-282.

46 Lund-Andersen H: Transport of glucose from blood to brain. Physiol Rev 1979;59: 305-352.

-47 Benomar Y, Naour N, Aubourg A, Bailleux V, Gertler A, Djiane J, Guerre-Millo $M$, Taouis M: Insulin and leptin induce Glut4 plasma membrane translocation and glucose uptake in a human neuronal cell line by a phosphatidylinositol 3-kinase-dependent mechanism. Endocrinology 2006;147:25502556.

-48 Messari El S, Ait-Iklef A, Ambroise DH, Penicaud L, Arluison M: Expression of insulin-responsive glucose transporter Glut4 mRNA in the rat brain and spinal cord: an in situ hybridization study. J Chem Neuroanat 2002;24:225-242.
49 Piroli GG, Grillo CA, Reznikov LR, Adams S, McEwen BS, Charron MJ, Reagan LP: Corticosterone impairs insulin-stimulated translocation of GLUT4 in the rat hippocampus. Neuroendocrinology 2007;85:71-80.

50 Grillo CA, Piroli GG, Hendry RM, Reagan LP: Insulin-stimulated translocation of GLUT4 to the plasma membrane in rat hippocampus is PI3-kinase dependent. Brain Res 2009;1296:35-45.

51 McEwen BS, Reagan LP: Glucose transporter expression in the central nervous system: relationship to synaptic function. Eur J Pharmacol 2004;490:13-24.

52 Murata H, Hruz PW, Mueckler M: The mechanism of insulin resistance caused by HIV protease inhibitor therapy. J Biol Chem 2000;275:20251-20254.

53 Murata H, Hruz PW, Mueckler M: Indinavir inhibits the glucose transporter isoform Glut4 at physiologic concentrations. AIDS 2002;16:859-863.

54 Skeberdis VA, Lan J, Zheng X, Zukin RS, Bennett MV: Insulin promotes rapid delivery of N-methyl-D -aspartate receptors to the cell surface by exocytosis. Proc Natl Acad Sci USA 2001;98:3561-3566.

- 55 Passafaro M, Piëch V, Sheng M: Subunit-specific temporal and spatial patterns of AMPA receptor exocytosis in hippocampal neurons. Nat Neurosci 2001;4:917-926.
56 Liu L, Brown III JC, Webster, WW, Morrisett RA; Monaghan DT: Insulin potentiates Nmethyl-D-aspartate receptor activity in Xenopus oocytes and rat hippocampus. Neurosci Lett 1995;192:5-8.

57 Zadran S, Qin Q, Bi X, Zadran H, Kim Y, Foy MR, Thompson R, Baudry M: 17-Beta-estradiol increases neuronal excitability through MAP kinase-induced calpain activation. Proc Natl Acad Sci USA 2009;106:2193621941.

58 Irving AJ, Wallace L, Durakoglugil D, Harvey J: Leptin enhances NR2B-mediated Nmethyl-D-aspartate responses via a mitogenactivated protein kinase-dependent process in cerebellar granule cells. Neuroscience 2006;138:1137-1148.

59 Lee CC, Huang CC, Wu MY, Hsu KS: Insulin stimulates postsynaptic density-95 protein translation via the phosphoinositide 3-kinase-Akt-mammalian target of rapamycin signaling pathway. J Biol Chem 2005;280: 18543-18550.

60 Hori K, Yasuda H, Konno D, Maruoka H, Tsumoto T, Sobue K: NMDA receptor-dependent synaptic translocation of insulin receptor substrate $\mathrm{p} 53$ via protein kinase $\mathrm{C}$ signaling. Neurosci 2005;25:2670-2681. 